"Income taxation of couples, spouses' labor supplies and the gender wage gap"

Helmuth Cremer and Kerstin Roeder 


\title{
Income taxation of couples, spouses' labor supplies and the gender wage gap*
}

\author{
Helmuth Cremer ${ }^{\dagger} \quad$ Kerstin Roeder ${ }^{\ddagger}$
}

September 2018

\begin{abstract}
We study the taxation of couples when female wages do not reflect their true productivity. We show that the expression for the marginal tax rates of the male spouses is the same as in a Mirrleesian world where wages reflect true productivities. Marginal taxes for the female spouses are reduced because of a Pigouvian correction. Consequently, the wage discrimination pleads for a lower marginal tax on the female spouse. Furthermore, the distortion of a couples' tradeoff between male and female labor supply is the same as in a Mirrleesian world without a gender wage gap. It only depends on true productivities and not on wages. In other words, the tax system completely neutralizes the extra distortion introduced by the wedge between the female spouse's wage and her true productivity.
\end{abstract}

JEL-Classification: H21, H31, D10, J16, J22

Keywords: Couples' income taxation, gender wage gap, optimal income taxation, household labor supply

\section{Introduction}

While plain discrimination appears to be declining, gender inequalities in the labor market remain substantial. These differences cannot be explained solely by gender differences in schooling, experience and job characteristics; see Blau and Kahn (2017). Instead the main "suspect" to explain the persistence of the gender wage gap (GWG) is the so-called "child penalty", see for instance Kleven et al. (2018). Women who have interrupted their career for full- or part-time child care, suffer from a wage penalty which lingers for decades when then they start to care for their dependant parent and suffer "the good daughter penalty". While part of this child penalty is explained by persistent part time work of more family friendly career choices, it also includes a discrimination

\footnotetext{
*Financial support from the Chaire "Marché des risques et creation de valeur" of the FdR/SCOR is gratefully acknowledged.

${ }^{\dagger}$ Toulouse School of Economics, University of Toulouse Capitole, 21 allée de Brienne, 31015 Toulouse, France, helmuth.cremer@tse-fr.eu.

${ }^{\ddagger}$ University of Augsburg, Germany, kerstin.roeder@wiwi.uni-augsburg.de
} 
part in that it introduces a wedge between wages and true productivities. For instance, Waldfogel (1997) concludes, based on longitudinal data that "even after controlling for part-time employment, a negative effect of children on women's pay remains."

There appears to be a large societal consensus that this GWG ought to be eradicated or, at least, mitigated. This probably requires some drastic and potentially costly reforms of labor market and child care policies. Anyway, the trends observed over the last decades show that, even in the best case scenarios the GWG will continue to be around for quite a while.

Since the "disease" requires a long cure and convalescence, it appears to be desirable to treat and alleviate its "symptoms" in the meantime. In this note, we study one possible approach to such a symptomatic treatment, namely the proper design of the tax system and, particularly, the tax treatment of couples.

To make this point in the simplest possible way, we consider a population of unitary couples where male wages reflect their true productivity, while female spouses receive a wage which is a given (possibly couple specific) proportion of their true productivity. In other words, the wage differential is exogenous and the factor of proportionality lumps together all the factors affecting the GWG including plain discrimination and, most significantly, the child penalty or at least the part of it which cannot be explained by part-time work or career choices.

Our model is otherwise similar to Cremer et al. (2012) in that we study the Mirrleesian optimal taxation of male and female incomes and, particularly, the way it affects the spouses' relative labor supplies. These are already distorted because of the GWG, and we examine if it is possible and desirable to undo these distortions via the tax system.

Couples' income taxation has of course already been widely studied in the literature; see Cremer et al. (2016) for an overview of the most significant contributions. From a methodological perspective the innovative feature of this note is that it explicitly accounts for gender wage discrimination and distinguishes between wages and true productivities. This aspect has to our knowledge so far been neglected in the literature and our analysis represents a first step to address this omission.

\section{Model}

Consider a population consisting of $N$ types of couples, indexed $i=1, \ldots, N$. The proportion of type- $i$ couples is $\pi^{i}$. Spouses are indexed by the subscript $j=f, m$. 
A couple's type is determined by the vector $\left(n_{f}^{i}, n_{m}^{i}, w_{f}^{i}, w_{m}^{i}\right)$, where $n_{j}^{i}$ is spouse $j$ 's true productivity. Technologies are linear so that marginal and average products are identical and constant. Furthermore, $w_{j}^{i}=\alpha_{j}^{i} n_{j}^{i}$ represents the wage rate that spouses receive for their $\ell_{j}^{i}$ units of labor so that gross earnings are $y_{j}^{i}=w_{j}^{i} \ell_{j}^{i}$. We make the traditional assumption that gross earnings are observable while wages and labor supplies are not. Wages may or may not reflect a spouse's real productivity. To capture in the most parsimonious way the GWG, we assume that $\alpha_{f}^{i} \leq \alpha_{m}^{i}=1$. When $\alpha_{f}^{i}<1$ the female spouse receives a lower wage for any given level of productivity than the male spouse. We impose no restriction on the distribution of productivities, except that it is discrete. In particular, the number of types can be arbitrary large (but finite) and spouses productivities may or may not be correlated.

The utility of couple $i$ is given by $U\left(x^{i}, \ell_{m}^{i}, \ell_{f}^{i}\right)$, where $x^{i}$ is the consumption of a numeraire (private) good. The utility function is such that $\partial U^{i} / \partial x^{i}>0$ and $\partial U^{i} / \partial \ell_{j}^{i}<$ 0 . To express utilities as functions of observable variables, define:

$$
V^{i}\left(x^{i}, y_{m}^{i}, y_{f}^{i}\right) \equiv U\left(x^{i}, \frac{y_{m}^{i}}{w_{m}^{i}}, \frac{y_{f}^{i}}{w_{f}^{i}}\right) .
$$

Observe that:

$$
\frac{\partial V^{i}}{\partial y_{j}^{i}}=\frac{\partial U^{i}}{\partial \ell_{j}} \frac{1}{w_{j}}<0, \quad j=f, m .
$$

\subsection{Couple's optimization}

The couple faces an income tax schedule $T\left(y_{f}^{i}, y_{m}^{i}\right)$ so that its disposable income available for consumption $x^{i}$ is:

$$
x^{i}=\sum_{j=f, m} y_{j}^{i}-T\left(y_{m}^{i}, y_{f}^{i}\right) .
$$

The couple chooses its labor supplies, $y_{m}^{i}, y_{f}^{i}$ and consumption $x^{i}$ to maximize $V^{i}$ subject to the budget constraint (2). The first-order conditions (FOCs) associated with this problem can be written as:

$$
M R S_{x y_{j}}^{i}=-\frac{\partial V^{i} / \partial y_{j}^{i}}{\partial V^{i} / \partial x^{i}}=1-T_{y_{j}}^{i} \quad i=1, \ldots, N ; j=f, m
$$

where $T_{y_{j}}^{i} \equiv \partial T^{i} / \partial y_{j}^{i}$ denotes the marginal tax rate faced by spouse $j$ in couple $i$. 


\section{Optimal tax problem}

We consider (constrained) Pareto efficient allocations obtained by maximizing the following welfare function

$$
\mathcal{W}=\sum_{i=1}^{N} \beta^{i} \pi^{i} V^{i}\left(x^{i}, y_{m}^{i}, y_{f}^{i}\right),
$$

where $\beta_{i}$ is the weight attached to couple $i$. While each spouse's before tax income $y_{j}^{i}$ is publicly observable, wages and labor supplies are not. The statistical distribution of types, on the other hand, is common knowledge. Under the considered information structure, the government's instrument consists of a possibly nonlinear income tax scheme $T\left(y_{f}^{i}, y_{m}^{i}\right)$ which can be positive or negative.

Feasible allocations must satisfy the following incentive constraints

$$
V^{i}=V^{i}\left(x^{i}, y_{m}^{i}, y_{f}^{i}\right) \geq V^{i b}=V^{i}\left(x^{b}, y_{m}^{b}, y_{f}^{b}\right) \quad \forall \quad i \neq b .
$$

That is any type- $i$ couple must be prevented from mimicking any type- $b$ couple. In addition, the resource constraint

$$
\sum_{i=1}^{N}\left[\frac{y_{m}^{i}}{\alpha_{m}^{i}}+\frac{y_{f}^{i}}{\alpha_{f}^{i}}-x^{i}\right] \geq 0
$$

must hold. Note that the resource constraint depends on true productivities of the spouses. To maintain the disconnection between households and firms, which is traditional in optimal tax models, we assume that firms' profits are taxed at $100 \%$; see Diamond and Mirrlees (1971).

The government maximizes (4) subject to (5) and (6). The Lagrangean can be written as:

$$
\mathcal{L}=\sum_{i=1}^{N} \beta^{i} \pi^{i} V^{i}+\mu \pi^{i} \sum_{i=1}^{N}\left[\frac{y_{m}^{i}}{\alpha_{m}^{i}}+\frac{y_{f}^{i}}{\alpha_{f}^{i}}-x^{i}\right]+\sum_{i=1}^{N} \sum_{b=1, b \neq i}^{N} \lambda_{i b}\left[V^{i}-V^{i b}\right],
$$

where $\mu>0$ is the Lagrange multiplier of the resource constraint while $\lambda_{i b} \geq 0$ is the Lagrange (Kuhn-Tucker) multiplier associated with the self-selection constraint from a type- $i$ to a type- $b$ couple. ${ }^{1}$ The FOCs with respect to $x^{i}$ and $y_{j}^{i}$ are given by:

$$
\begin{aligned}
\frac{\partial \mathcal{L}}{\partial x^{i}} & =\beta^{i} \pi^{i} \frac{\partial V^{i}}{\partial x^{i}}+\sum_{b=1, b \neq i}^{N} \lambda_{i b} \frac{\partial V^{i}}{\partial x^{i}}-\sum_{b=1, b \neq i}^{N} \lambda_{b i} \frac{\partial V^{b i}}{\partial x^{i}}-\mu \pi^{i}=0, \\
\frac{\partial \mathcal{L}}{\partial y_{j}^{i}} & =\left[\beta^{i} \pi^{i}+\sum_{b=1, b \neq i}^{N} \lambda_{i b}\right] \frac{\partial V^{i}}{\partial y_{j}^{i}}-\sum_{b=1, b \neq i}^{N} \lambda_{b i} \frac{\partial V^{b i}}{\partial y_{j}^{i}}+\mu \pi^{i} \frac{1}{\alpha_{j}^{i}}=0 .
\end{aligned}
$$

\footnotetext{
${ }^{1}$ Since the incentive constraints are inequalities this is a Kuhn Tucker problem so that either the constraint is binding or the associated multiplier is equal to zero.
} 
The FOCs along with the constraints determine the (constrained) Pareto efficient allocation. These conditions and all our subsequent results are very general. They do not depend on the pattern of binding incentive constraints nor on the type of mating, and they are valid for all constrained Pareto-efficient allocations.

Appendix 4 shows that by combining the two FOCs, the marginal rate of substitution between gross income and consumption can be expressed as

$$
M R S_{x y_{j}}^{i}=\frac{\beta^{i} \pi^{i}+\sum_{b=1, b \neq i}^{N} \lambda_{i b}-\sum_{b=1, b \neq i}^{N} \lambda_{b i} \frac{\partial V^{b i} / \partial x^{i}}{\partial V^{i} / \partial x^{i}}}{\alpha_{j}^{i}\left[\beta^{i} \pi^{i}+\sum_{b=1, b \neq i}^{N} \lambda_{i b}-\sum_{b=1, b \neq i}^{N} \lambda_{b i} \frac{M R S_{x y_{j}}^{b i}}{M R S_{x y_{j}}^{i}}\right]} \equiv \frac{1}{\alpha_{j}^{i}} A_{j}^{i} .
$$

\subsection{Marginal tax rates}

Combining equations (3) and (9) we can determine the marginal tax rate of the implementing tax function. The full information solution which is a useful benchmark can be obtained from (9), by setting all $\lambda$ 's equal to zero $\left(\lambda_{b i}=\lambda_{i b}=0 \forall i, b=1, \ldots, N\right)$. This yields:

$$
M R S_{x y_{j}}^{i}=\frac{1}{\alpha_{j}^{i}}
$$

which, from equation (3) implies:

$$
T_{y_{j}}^{i}=\frac{\alpha_{f}^{i}-1}{\alpha_{f}^{i}} \equiv T_{y_{j}}^{P i} .
$$

We define (10) as the Pigouvian tax rate. Indeed, in a full information setting the GWG is formally equivalent to an (non-anonymous) externality. First-best Pareto efficiency can then be reestablished by a simple, albeit individualized, Pigouvian tax and any redistribution can be done via lump-sum taxes and transfers. With our illustrative assumption that $\alpha_{f}^{i} \leq \alpha_{m}^{i}=1$ we have $T_{y_{m}}^{P i}=0$ and $T_{y_{f}}^{P i} \leq 0$. No Pigouvian correction is needed for the male spouse, while a Pigouvian subsidy applies to all female workers for whom $\alpha_{j}^{i}<1$.

Returning to the asymmetric information case, equations (3) and (9) result in:

$$
T_{y_{j}}^{i}=1-M R S_{I y_{j}}^{i}=1-\frac{1}{\alpha_{j}^{i}} A_{j}^{i} .
$$

Let us define the (traditional) Mirrleesian tax rate without gender wage gap, as $T_{y_{j}}^{M i}=$ $1-A_{j}^{i}$. It describes the solution to the optimal tax problem when $\alpha_{j}^{i}=1$, for all spouses in all couples $(i=1, \ldots, N$ and $j=f, m)$. Using (10) expression (11) can be written as:

$$
T_{y_{j}}^{i}=1-\frac{1}{\alpha_{j}^{i}} A_{j}^{i}=\frac{T_{y_{j}}^{M i}}{\alpha_{j}^{i}}-\frac{1-\alpha_{j}^{i}}{\alpha_{j}^{i}}=\frac{T_{y_{j}}^{M i}}{\alpha_{j}^{i}}+T_{y_{j}}^{P i} .
$$


Let us first consider the top-couple, that is the couple (if any) whom nobody wants to mimic implying $\lambda_{b i}=0 \forall b \neq i .^{2}$ For spouse $j=f, m$ within this couple, we have

$$
\begin{aligned}
T_{y_{m}}^{i} & =0, \\
T_{y_{f}}^{i} & =\frac{\alpha_{f}^{i}-1}{\alpha_{f}^{i}}<0 .
\end{aligned}
$$

For the male spouse the traditional "no distortion at the top" result emerges, while for the female spouse we get a marginal Pigouvian subsidy if $\alpha_{f}^{i}<1$.

For all other couples the expressions for the marginal tax rate include a Mirrleesian (incentive) term and a Pigouvian term. Observe that while the Pigouvian term is exactly at its first-best level, the Mirrleesian analogy applies only to the rule. ${ }^{3}$ The fact that the Mirrleesian tax rate is divided by $\alpha_{j}^{i}$ may at first come as a surprise, but it has a simple explanation. The Mirrleesian rate applies by definition to $y_{j}^{i}=w_{j}^{i} \ell_{j}^{i}$. However, since the Pigouvian correction is also applied, the "true" income of spouse $j$ is $n_{j}^{i} \ell_{j}^{i}=w_{j}^{i} \ell_{j}^{i} / \alpha_{j}^{i}$. The incentive part of the optimal tax rule then simply says that the Mirrleesian rate is applied to the "true" income of the spouse (as measured by their marginal product multiplied by labor supply).

When the assumption $\alpha_{f}^{i} \leq \alpha_{m}^{i}=1$ is imposed we then have

$$
\begin{aligned}
& T_{y_{m}}^{i}=T_{y_{m}}^{M i}, \\
& T_{y f}^{i} \leq T_{y_{f}}^{M i} \quad \text { so that } \quad T_{y f}^{i} \gtreqless 0 \quad \Leftrightarrow \quad T_{y_{f}}^{M i} \gtreqless 1-\alpha_{f}^{i} .
\end{aligned}
$$

The marginal tax rate of the female spouse is always smaller than the Mirrleesian rate. In the traditional case where the Mirrleesian rate is positive, there is then a conflict between incentive and Pigouvian considerations. If the wage gap is large it may outweigh the traditional tax argument and imply a negative marginal tax rate for the female spouse. ${ }^{4}$

Another way to look at these results is to examine how female discrimination $\left(\alpha_{f}^{i} \leq\right.$ $\alpha_{m}^{i}=1$ ) affects the spouses' relative marginal tax rates. The conventional wisdom, which goes back to Boskin and Sheshinski (1983) (B\&S) is that women should face lower marginal tax rates than their spouse because their labor supply is more elastic.

\footnotetext{
${ }^{2}$ In a fully fledged multi-dimensional setting there is no guarantee that such a couple exists. This has no impact on any of the other results.

${ }^{3}$ A caveat which applies to almost all results in optimal tax theory.

${ }^{4}$ Since we consider a multi-dimensional setting and have made no assumption on the distribution of types there is no guarantee that all Mirrleesian marginal tax rates are positive. When the Mirrleesian rate for the female spouse is negative, there is no conflict between the two terms and expression (16) necessarily implies a negative marginal tax for the female spouse.
} 
Cremer et al. (2012) have shown that this result may be mitigated or even reversed for incentive reasons, in particular, when gender wage heterogeneity is smaller in highincome couples. In their setting there is a gender productivity gap but it reflects "true" productivities and not discrimination. Our results, go exactly in the opposite direction in the sense that they tend to reinforce or reinstate the B\&S result. Discrimination brings in the Pigouvian term which reduces the marginal tax rate applied to the female spouse.

Proposition 1 (i) When couples' types are observable and the female spouse in couple $i$ suffers from wage discrimination, that is $\alpha_{f}^{i}<1$, her income will be subject to a Pigouvian subsidy to correct for the misallocation of her labor supply.

(ii) When couples' types are not observable a spouse's marginal income tax rate is defined by expression (12), which shows that it depends on a Pigouvian and on a Mirrleesian (incentive related) term. The Mirrleesian term can either be positive or negative, while the Pigouvian term is always negative for $\alpha_{f}^{i}<1$. If the gender wage gap is large it may outweigh the traditional tax argument and imply a negative marginal tax rate for the female spouse.

(iii) Our results reinforce (or tend to reinstate) the BESS result that female spouses should have a smaller marginal tax rate than males.

\subsection{The tradeoff between female and male labor supply}

Combining expressions (1) and (3) shows that in the absence of taxation a couple chooses $\ell_{f}$ and $\ell_{m}$ so that:

$$
M R S_{\ell_{f} \ell_{m}}^{i}=\frac{\partial U^{i} / \partial \ell_{m}}{\partial U^{i} / \partial \ell_{f}}=\frac{w_{m}^{i}}{w_{f}^{i}} .
$$

We can think about condition as a kind of "production efficiency" condition within the household. It describes the efficient tradeoff of a couple which has to earn a given gross income $y_{m}+y_{f}$ in a "least costly", utility maximizing, way. When wages reflect marginal products, condition (17) is also necessary for Pareto efficiency. In our setting with the GWG Pareto efficiency, however, requires:

$$
M R S_{\ell_{f} \ell_{m}}^{i}=\frac{n_{m}^{i}}{n_{f}^{i}} .
$$

In a full information world the Pareto efficient tradeoff can then be decentralized by imposing a Pigouvian tax as defined by equation (10). To see this, observe that (1) 
and (3) imply that in the presence of taxation spouses' levels of labor supply are set according to:

$$
M R S_{\ell_{f} \ell_{m}}^{i}=\frac{1-T_{y_{m}}^{i}}{1-T_{y_{f}}^{i}} \frac{w_{m}^{i}}{w_{f}^{i}}
$$

Using (10) and the property $w_{j}^{i}=\alpha_{j}^{i} n_{j}^{i}$ shows that the above equation coincides with (18) when $T_{y_{j}}^{i}=T_{y_{j}}^{P i} \forall j$.

We know from Cremer et al. (2012) that the optimal tax policy will in general distort the tradeoff between male and female labor supply. As these authors show this distortion arises for incentive reasons; it is a way to relax an otherwise binding incentive constraint. With no GWG, we have from (1) and (3): ${ }^{5}$

$$
M R S_{\ell_{f} \ell_{m}}^{i}=\frac{1-T_{y_{m}}^{M i}}{1-T_{y_{f}}^{M i}} \frac{w_{m}^{i}}{w_{f}^{i}} .
$$

With the GWG, combining (1), (3) and (12) we successively obtain:

$$
\begin{aligned}
M R S_{\ell_{f} \ell_{m}}^{i} & =\frac{1-T_{y_{m}}^{i}}{1-T_{y_{f}}^{i}} \frac{w_{m}^{i}}{w_{f}^{i}} \\
& =\frac{1-T_{y_{m}}^{M i}}{1-T_{y_{f}}^{M i}} \frac{\alpha_{f}}{\alpha_{m}} \frac{w_{m}^{i}}{w_{f}^{i}}=\frac{1-T_{y_{m}}^{M i}}{1-T_{y_{f}}^{M i}} \frac{n_{m}^{i}}{n_{f}^{i}} .
\end{aligned}
$$

Comparing equations (19) and (20) shows that with the GWG the distortion of couples' tradeoff between male and female labor supply with respect to the true productivities is the same as in a Mirrleesian world without a GWG. Intuitively, this is in line with the results presented in the previous subsection. Since the marginal tax rates, as defined by (12), already involve a Pigouvian correction for the GWG, a couple's tradeoff between male and female labor supply is effectively based on the spouses (relative) true productivities. In a full information setting, this tradeoff would remain undistorted. Under asymmetric information, the arguments presented in Cremer et al. (2012) carry over and imply that it should, in general, be distorted. But the crucial point is that these are traditional incentive corrections which are not directly affected by the GWG; the reference they are applied to is the spouses' relative productivities and not their wages. ${ }^{6}$ To sum up, while the tax system distorts the spouses' relative labor supplies for incentive reasons it completely neutralizes the distortion introduced by the wedge between the female spouse's wage and her true productivity.

\footnotetext{
${ }^{5}$ Recall that with no GWG $\alpha_{f}^{i}=\alpha_{m}^{i}=1$ so that $T_{y_{j}}^{i}=T_{y_{j}}^{M i}$.

${ }^{6}$ Once again this result applies to rules; actual levels may differ.
} 
Proposition 2 The distortion of a couples' tradeoff between male and female labor supply is the same as in a Mirrleesian world without a GWG. It only depends on true productivities and not on wages.

\section{Conclusion}

We have studied the design of couples' income taxation when there is a GWG which reflects the fact that female wages do not reflect their true productivities. Marginal tax rates for males follow the same rule as in a Mirrleesian world. Those for women include a Mirrleesian and a Pigouvian term. The Mirrleesian expression is the same as when wages reflect true productivities. The Pigouvian term, which is always negative, corrects for the wedge between wages and productivities. Consequently, the GWG tends to reduce the optimal marginal tax on women. Finally, a couples' tradeoff between male and female labor supply is the same as in a Mirrleesian world without a GWG. It only depends on true productivities and not on wages. While the tax system distorts the spouses' relative labor supplies for incentive reasons it completely neutralizes the distortion introduced by the wedge between the female spouse's wage and her true productivity.

The main lesson that emerges from our paper is that the GWG reduces the female spouse's marginal tax rate by a Pigouvian correction. This correction undoes the distortion in spouses' relative labor supply caused by the GWG. While this does not eliminate the GWG, it means that it is possible and desirable to restore a tradeoff between spouses' labor supplies that reflects their true productivities.

To sum up, and to return to the question raised in the introduction, an appropriately designed general income tax can and should neutralize the distortions created by wage discrimination. In particular, "production efficiency" for the spouses' relative labor supplies is reestablished.

\section{Appendix}

Derivation of $M R S_{x y_{j}}^{i}$ : Equations (7) and (8) can be rearranged as:

$$
\begin{aligned}
\frac{\mu \pi^{i}}{\partial V^{i} / \partial x_{i}} & =\beta^{i} \pi^{i}+\sum_{b=1, b \neq i}^{N} \lambda_{i b}-\sum_{b=1, b \neq i}^{N} \lambda_{b i} \frac{\partial V^{b i} / \partial x^{i}}{\partial V^{i} / \partial x^{i}} \\
\frac{\mu \pi^{i}}{\partial V^{i} / \partial x_{i}} & =-\alpha_{j}^{i}\left[\beta^{i} \pi^{i}+\sum_{b=1, b \neq i}^{N} \lambda_{i b}\right] \frac{\partial V^{i} / \partial y_{j}^{i}}{\partial V^{i} / \partial x^{i}}+\alpha_{j}^{i} \sum_{b=1, b \neq i}^{N} \lambda_{b i} \frac{\partial V^{b i} / \partial y_{j}^{i}}{\partial V^{i} / \partial x^{i}}
\end{aligned}
$$


With the definition of the marginal rate of substitution, we can rewrite (A2) as:

$$
\frac{\mu \pi^{i}}{\partial V^{i} / \partial x_{i}}=-\alpha_{j}^{i} M R S_{x y_{j}}^{i}\left[\beta^{i} \pi^{i}+\sum_{b=1, b \neq i}^{N} \lambda_{i b}+\sum_{b=1, b \neq i}^{N} \lambda_{b i} \frac{M R S_{x y_{j}}^{b i}}{M R S_{x y_{j}}^{i}}\right]
$$

Combining (A1) and (A3) and solving for $M R S_{x y_{j}}^{i}$ yields expression (9).

\section{References}

[1] Blau, F.D. and L.M. Kahn, "The gender wage gap: extent, trends, and explanations," Journal of Economic Literature, 2017, 55, 789-865.

[2] Boskin, M. and E. Sheshinski, "Optimal tax treatment of the family: married couples," Journal of Public Economics, 1983, 20, 281-297.

[3] Cremer, H., J.M. Lozachmeur and P. Pestieau, 2012, "Income taxation of couples and the tax unit choice," Journal of Population Economics, 25, 763-771.

[4] Cremer, H., J.M. Lozachmeur, D. Maldonado and K. Roeder, 2016, "Household bargaining and the design of couples' income taxation," European Economic Review, 89, 454-470.

[5] Diamond, P.A. and J.A. Mirrlees, 1971, "Optimal taxation and public production I: production efficiency," The American Economic Review, 61 (1), 8-27.

[6] Kleven, H., C. Landais, and J.E. Søgaard, "Children and gender inequality: evidence from Denmark", NBER WP 24219, 2018.

[7] Waldfogel, J., "The effect of children on women's wages," American Sociological Review, 1997, 62 (2), 209-217. 